OPEN ACCESS

Edited by:

Linda Charvoz,

University of Applied Sciences and Arts of Western Switzerland,

Switzerland

Reviewed by:

Nina Rottmann,

University of Southern Denmark,

Denmark

Dalnim Cho,

The University of Texas MD Anderson

Cancer Center, United States

${ }^{*}$ Correspondence:

Karen S. Lyons

karen.lyons@bc.edu

Specialty section:

This article was submitted to

Psycho-Oncology,

a section of the journal

Frontiers in Psychology

Received: 16 November 2021

Accepted: 24 January 2022

Published: 17 February 2022

Citation:

Lyons KS, Gorman JR, Larkin BS,

Duncan G and Hayes-Lattin B (2022)

Active Engagement, Protective

Buffering, and Depressive Symptoms

in Young-Midlife Couples Surviving

Cancer: The Roles of Age and Sex.

Front. Psychol. 13:816626.

doi: 10.3389/fpsyg.2022.816626

\section{Active Engagement, Protective Buffering, and Depressive Symptoms in Young-Midlife Couples Surviving Cancer: The Roles of Age and Sex}

\author{
Karen S. Lyons ${ }^{1 *}$, Jessica R. Gorman ${ }^{2}$, Brandon S. Larkin ${ }^{3}$, Grace Duncan ${ }^{1}$ and \\ Brandon Hayes-Lattin ${ }^{4}$
}

${ }^{1}$ Connell School of Nursing, Boston College, Chestnut Hill, MA, United States, ${ }^{2}$ School of Social and Behavioral Health Sciences, College of Public Health and Human Sciences, Oregon State University, Corvallis, OR, United States, ${ }^{3}$ School of Nursing, Oregon Health \& Science University, Portland, OR, United States, ${ }^{4}$ School of Medicine, Oregon Health \& Science University, Portland, OR, United States

Objective: Cancer researchers have found midlife couples to have poorer outcomes compared to older couples due to the off-time nature of the illness for them. It is unknown if young couples (aged 18-39), who are under-represented in cancer studies and overlooked for supportive programs, are at further risk. This study explored the moderating roles of survivor age and sex on the associations between active engagement and protective buffering and depressive symptoms in couples surviving cancer.

Methods: The exploratory study comprised 49 couples (aged 27-58) 1-3 years postdiagnosis. Multilevel modeling was used to explore the moderating roles of survivor age and sex, controlling for interdependent data.

Results: Approximately, $37 \%$ of survivors and $27 \%$ of partners met clinical criteria for further assessment of depression, with $50 \%$ of couples having at least one member meeting the criteria. Survivors and their partners did not significantly differ on depressive symptoms, active engagement, or protective buffering. Male survivors reported significantly higher levels of active engagement by their partners than female survivors and female survivors reported significantly higher levels of protective buffering by their partners than male survivors. We found some evidence to suggest that survivor age and sex may play moderating roles between active engagement and protective buffering and depressive symptoms. Older partners and female survivors appeared to experience more positive effects from engaging in positive dyadic behaviors than younger partners and male survivors.

Conclusion: Findings not only confirm the important role of dyadic behaviors for couples surviving cancer together, but also the important roles of survivor age and sex may play in whether such behaviors are associated with lower levels of depressive symptoms. Future research that examines these complex associations over time and across the adult life span in diverse populations is needed.

Keywords: dyadic coping, dyadic illness management, depression, communication, protective buffering, active engagement 


\section{INTRODUCTION}

It is estimated that there will be over 22 million cancer survivors in the US by 2030 (American Cancer Society, 2021). A cancer diagnosis ripples throughout the family with couples surviving cancer facing uncertainty, disruption to family goals, and high levels of fear the cancer will recur (Champion et al., 2014; Kent et al., 2016; Shapiro, 2018; Lyons et al., 2022). In addition, partners typically face the strain of providing care and support, redistribution of roles, and household tasks, but also the possibility of losing the survivor. Both survivor and partner worry about the impact of the experience on their relationship, children they may have, and the course of the family trajectory and family goals (Corney et al., 2016; Collaço et al., 2019; Gorman et al., 2020). Although not all couples living with cancer report high psychological distress or depression, and some report the experience having a positive impact on their lives and relationship (Lyons et al., 2022), research has found that some cancer survivors and partners experience high levels of anxiety and depression, even years beyond treatment (Costanzo et al., 2009; Mitchell et al., 2013; Champion et al., 2014; Kim et al., 2016; Shapiro, 2018; Lee and Lyons, 2019). A metaanalysis of predominantly mid-late life survivors reported an $11.6 \%$ (95\% CI 7.7-16.2\%) prevalence of depression for survivors versus $10.2 \%$ (95\% CI $8.0-12.6 \%$ ) for healthy controls; prevalence for survivors and their partners was not statistically significant (Mitchell et al., 2013). Much less is known about young adult couples, who are often under-represented in studies and overlooked for supportive programs (Barnett et al., 2016; Smith et al., 2016; Hydeman et al., 2019; Gorman et al., 2020), despite incidence rates of cancer increasing in this age group (Howlader et al., 2019; Scott et al., 2020).

With strong evidence of the interdependent nature of health within couples and protective role of open communication (e.g., active engagement) and collaborative behaviors (e.g., shared activities; Berg and Upchurch, 2007; Kim et al., 2016; Lyons et al., 2016b, 2018; Shaffer et al., 2016; Winters-Stone et al., 2016; Langer et al., 2017; Lyons and Lee, 2018; Acquati and Kayser, 2019; Falconier and Kuhn, 2019; Lee and Lyons, 2019; Gorman et al., 2020; Lee et al., 2020; Streck et al., 2020; Wilson et al., 2020; Hornbuckle et al., 2021; Stefanut et al., 2021), it is especially important to focus on the couple as a unit to identify at-risk couples who may be less able to support one another. Numerous dyadic theories have contributed greatly to the dyadic science of illness over the past two decades (Bodenmann, 1997; Revenson et al., 2005; Berg and Upchurch, 2007; Regan et al., 2015; Traa et al., 2015; Badr and Acitelli, 2017; Falconier and Kuhn, 2019). In particular, many of these dyadic theories highlight the importance of support and collaboration within couples through positive dyadic coping (i.e., open communication, supportive behaviors, and a sense of "we-ness") and the need to focus on the couple as a unit (Acitelli and Badr, 2005). The current study was guided by the theory of dyadic illness management (TDIM; Lyons and Lee, 2018), which similarly moves beyond an individual perspective of illness to focus on the couple as the unit of focus. The overall goal of the theory is to optimize health within the couple by holding the health and needs of each member in balance and recognizing the heterogeneity that exists within groups and across couples.

The TDIM purports that how couples manage an illness like cancer influences the dyadic health of the couple. Integrating research on illness management, caregiving, and dyadic coping, the theory primarily focuses on the concept of dyadic management behaviors-a broad conceptualization of the collaborative verbal and non-verbal behaviors couples engage in to manage and cope with illness and survivor symptoms (i.e., communication, supportive behaviors, collaborative symptom and care management behaviors, and shared health activities; Lyons and Lee, 2018; Lyons et al., 2022). The theory also proposes the importance of shared dyadic appraisal and roles of contextual risk and protective factors at the individual (e.g., age and sex), dyadic, familial, and cultural levels in optimizing dyadic health.

Two examples of dyadic management behaviors are the relationship-focused strategies of active engagement and protective buffering (Coyne and Smith, 1991; Buunk et al., 1996). Active engagement represents open and supportive communication about the illness by one's partner, providing opportunities to share feelings, be listened to and validated. Thus, active engagement has been considered a type of positive dyadic coping behavior (Buunk et al., 1996; Hagedoorn et al., 2000; Falconier and Kuhn, 2019), as well as a positive dyadic illness management behavior (Lyons and Lee, 2018). Alternatively, protective buffering represents the partner's denial of or attempt to minimize illness concerns or worries, or avoidance of discussing the illness together. Thus, protective buffering has been considered a type of negative dyadic coping behavior (Buunk et al., 1996; Hagedoorn et al., 2000; Falconier and Kuhn, 2019) and negative dyadic illness management behavior (Lyons and Lee, 2018). More open and supportive communication (i.e., active engagement) has been consistently associated with more positive health in both survivors and partners (Traa et al., 2015; Lyons et al., 2016a; Acquati and Kayser, 2019; Falconier and Kuhn, 2019; Lee and Lyons, 2019; Meier et al., 2019; Streck et al., 2020; Dewan et al., 2021; Stefanut et al., 2021). However, the vast majority of studies on couples surviving cancer involves mid-late life couples and primarily breast or prostate cancer, where sex and role are often confounded. Thus, the link between active engagement and depressive symptoms by survivor age and sex is unclear, leading to one size fits all approaches (Chan et al., 2021). Furthermore, despite the term sounding positive, protective buffering has been found to be negatively associated with poor relationship outcomes, clinical-events, and depressive symptoms (Falconier et al., 2015; Lee and Lyons, 2019; Lyons et al., 2020, 2021). Given that men are sometimes more likely to "hold back" and avoid disclosures (Manne et al., 2004b, 2005, 2015), and some evidence that younger partners may engage more in protective buffering (Acquati and Kayser, 2019), exploring how these associations vary by survivor age or sex is also needed.

Transitions and experiences in life are interpreted with regard to timing in the life course (chronological, familial, and social) and the context in which they take place (Neugarten, 
1979; Hareven, 1994; Berg and Upchurch, 2007). Adults do not expect to experience cancer or assume a care role for their partner in young adulthood or midlife. Although youngmidlife couples may experience some commonality in the "off-time" nature of the illness, they do not share the same stage in the life span. Young adult couples (under 40) are more likely to be new to their adult roles, beginning careers and families, in shorter relationships, have less experience with collaborative coping skills and health behaviors, and are more susceptible to contextual factors, such as financial strain and illness (Berg and Upchurch, 2007; American Psychological Association, 2019; Hydeman et al., 2019). The long-term effects of cancer and implications for the young adult couple (e.g., fertility, disruptions to career and family goals, and changes in relationships) may be especially challenging (Barnett et al., 2016; Corney et al., 2016; Collaço et al., 2019; Hydeman et al., 2019).

Researchers have consistently found younger survivors and younger couples to have more negative outcomes compared with older survivors and older couples (Harden et al., 2006; Champion et al., 2014; Borstelmann et al., 2015; Rottmann et al., 2016; Lee and Lyons, 2019), but broad age ranges in studies make it difficult to purposely examine age risk when younger couples are often poorly represented. A notable exception includes a cross-sectional study of couples living with breast cancer that compared 35 young couples (aged 45 or younger) to 51 midlife couples (aged 46-66) within 3 months of diagnosis that found younger survivors had worse physical and mental health, greater negative impact of cancer and less social support than midlife survivors. Similarly, younger partners had worse mental health than midlife survivors (Acquati and Kayser, 2019). No differences in dyadic coping were found between age-groups for survivors, but younger partners had more negative dyadic coping than midlife partners (Acquati and Kayser, 2019). It is unknown if the theoretically purported benefits of positive dyadic behaviors, such as active engagement and low levels of protective buffering on depressive symptoms, vary by survivor age.

Similarly, cancer research has predominantly focused on breast and prostate cancer, where sex and role are often confounded (e.g., all survivors in the study are female), limiting the ability to fully understand the role of survivor sex in how couples experience and navigate cancer. Evidence suggests females, regardless of role, experience more negative outcomes than males (Hagedoorn et al., 2008; Falconier and Kuhn, 2019). Although female survivors have been found to engage in more positive dyadic behaviors, such as open communication and support (Acquati and Kayser, 2019), and to be more likely than males to collaborate and define themselves relationally (Kiecolt-Glaser and Newton, 2001; Berg and Upchurch, 2007), they may also be more vulnerable when such collaboration is absent (Kiecolt-Glaser and Newton, 2001; Berg and Upchurch, 2007; Lyons et al., 2018). Given the importance placed on collaborative dyadic behaviors (particularly behaviors, such as active engagement) as protective for couples experiencing cancer, more deliberate research on the role of survivor sex in couples across the life span is needed to address this gap.
Thus, the current study builds upon previous research and is guided by the TDIM to explore the moderating roles of survivor age and sex (i.e., individual contextual factors) on the associations between active engagement and protective buffering (i.e., dyadic illness management behaviors) and depressive symptoms of survivor and partner (i.e., dyadic health) in young-midlife couples 1 to 3 years after diagnosis.

\section{MATERIALS AND METHODS}

The current exploratory study recruited couples through the Oregon State Cancer Registry via targeted mailings. Per the cancer registry's protocol, letters describing the study were mailed by registry staff to survivors meeting initial eligibility criteria (i.e., diagnosis data, age, and zip code to optimize representation of both rural and urban-dwelling couples). A total of 700 letters were mailed with equal numbers sent to young survivors (aged 21-39 at diagnosis) and midlife survivors (aged 40-56 at diagnosis). Additionally, recruitment flyers were posted in an oncology clinic at Oregon Health and Science University (OHSU). All interested couples were screened for eligibility by research staff at OHSU. Eligibility criteria included that (1) the survivor had a primary diagnosis of invasive cancer in the preceding 18-36 months, (2) couples were co-residing at the time of diagnosis and recruitment, (3) couples were aged 21 to 56 years at diagnosis, (4) couples had the ability to read English, (5) couples had access to a telephone, and (6) couples were resident in Oregon. We selected the upper bound of 56 years of age to minimize inclusion of couples considering retirement at time of diagnosis. Couples were not required to be married and couples of any sexual orientation were eligible to participate.

A total of 160 survivors expressed interest in the study (158 from the targeted registry mailings-23\% response rateand two from the fliers posted in the oncology clinic). Thirtythree survivors $(21 \%)$ were lost to follow-up and could not be reached for a screening phone call, even after several attempts. A total of 77 couples (48\%), who were screened by phone, were eligible. The remaining 50 survivors (31\%) were screened as ineligible because they did not have a partner (36\%), were older than 56 at diagnosis (40\%), did not meet diagnosis criteria/reason unknown (10\%), could not read English (4\%), the survivor had died (6\%), or declined to participate $(4 \%)$. The 77 eligible couples were mailed a packet containing separate surveys for survivor and partner and separate consent forms. Couples were asked to complete surveys independently and return them with signed consent forms in the provided stampedaddressed envelopes. A total of 49 couples (64\%) returned surveys and signed consent forms for both survivor and partner. The study was approved by the Institutional Review Board at Oregon Health and Science University (e\#15498).

\section{Measures}

All sociodemographic information and measures for both members of the couple were obtained through their respective mail surveys. 


\section{Depressive Symptoms}

Depressive symptoms were measured with the Center for Epidemiological Studies Depression scale that has good internal consistency, sensitivity, specificity, and validity (Radloff, 1977; Beekman et al., 1997), including in couples with cancer (Lyons et al., 2014). Survivors and partners responded to 20 statements using a 0 (rarely or none) to 3 (most or all) scale (e.g., "I was bothered by things that do not usually bother me," "I felt depressed," and "I did not feel like eating/appetite was poor"). Scores were summed with higher scores indicating greater depressive symptomatology. A score of 16 or above indicates likely depression and the need for further assessment (Radloff, 1977). More recent research suggests a clinical cut-off score of 20 or above may have a more adequate trade-off of sensitivity and specificity for depression (Vilagut et al., 2016). Cronbach's alpha in the current study was 0.91 for survivors and 0.92 for partners.

\section{Dyadic Illness Management Behaviors}

Dyadic illness management behaviors are operationalized in two ways in the current study-active engagement and protective buffering. Active engagement and protective buffering were measured using the two subscales of the Dyadic Coping measure (Buunk et al., 1996; Hagedoorn et al., 2000). The active engagement subscale has five items that assess the extent to which the survivor and partner view each other's active involvement and support (e.g., "my partner tries to discuss cancer with me openly," "when something bothers me, my partner tries to discuss it with me", and "my partner is full of understanding towards me"). Participants respond to the five items using a Likert scale from 1 (never) to 5 (very often). Higher scores indicate higher levels of perceived active engagement by one's partner. The scale has exhibited strong internal consistency in studies of couples with cancer (Hagedoorn et al., 2000; Hinnen et al., 2007), including the current study (Cronbach's alpha for survivor $=0.89$; Cronbach's alpha for partner $=0.81$ ). The protective buffering subscale consists of six items that assess the extent to which the survivor and partner view each other's use of hiding concerns and denying worries (e.g., "my partner tries to hide his or her worries about me," "my partner just waves my worries aside," and "my partner tries to act like nothing is the matter"). Participants respond to six items using a Likert scale from 1 (never) to 5 (very often). Higher scores indicate higher levels of perceived protective buffering by one's partner. The scale has exhibited good internal consistency in studies of couples with cancer (Hinnen et al., 2007), including the current study (Cronbach's alpha for survivor=0.77; Cronbach's alpha for partner $=0.65$ ).

\section{Analysis Plan}

Descriptive statistics were used to characterize the sample (SPSS v26; IBM Corporation, Armonk, NY). Paired samples t-tests were used to compare survivor and partner depressive symptoms, active engagement and protective buffering due to the interdependent nature of the data. Multilevel modeling (Hierarchical Linear Modeling v8; Skokie, IL) was used to explore the moderating roles of survivor age and sex on the associations between active engagement and protective buffering and depressive symptoms at the level of the couple to control for interdependencies between survivor and partner data (Garcia et al., 2015). HLM uses full information maximum likelihood estimation, which estimates parameter values based on all existing data available to obtain unbiased estimates.

Two models were run to explore the moderating role of survivor age (as a continuous variable) on the association between each dyadic behavior (i.e., active engagement and protective buffering) and depressive symptoms. Each model included a moderated actor term that represented the interaction between survivor age and survivor report of the dyadic behavior (i.e., active engagement and protective buffering) and a moderated partner term that represented the interaction between survivor age and partner report of the dyadic behavior (i.e., active engagement and protective buffering; Garcia et al., 2015). A significant interaction effect was deemed evidence of moderation. Due to the small sample size, effect sizes $r=\sqrt{\frac{t^{2}}{\left(t^{2}+d f\right)}}$ were calculated and reported. Only results with medium $(r=0.30)$ or large $(r=0.50)$ effects were interpreted. Figures depict each variable's high (1 $S D$ above the mean) and low (1 SD below the mean) values. A similar procedure was used to examine the moderating role of survivor sex on the association between each dyadic behavior (i.e., active engagement and protective buffering) and depressive symptoms. Variables were centered prior to creating interaction terms except for survivor sex, which was coded as 0 (male) and 1 (female).

Survivor age was treated as a continuous variable in moderation analyses due to significant disadvantages of dichotomizing data including significant loss of information, variability, statistical power (especially in small samples), and higher risk of false positive results (Altman and Royston, 2006). Thus, the role of age in moderation analyses is interpreted as the role of increasing/decreasing age (or being older or younger) across young-mid adulthood.

\section{RESULTS}

\section{Sample Characteristics}

Table 1 displays the sociodemographic and background characteristics for the sample of 49 couples. Survivors and partners were, on average, $43.5(S D=9.0)$ and $43.9(S D=9.7)$ years old, respectively, with $43 \%$ of the sample between the ages of 27 and 40 . Survivors were predominantly female (69\%), white (90\%), non-Hispanic (88\%), employed (61\%), and had completed college. Average time since diagnosis was 2.26 $(S D=0.60)$ years. Partners were predominantly male $(67 \%)$, white (82\%), non-Hispanic (88\%), employed (76\%), and completed college (59\%). Almost half of couples lived in designated rural areas. The small number of Hispanic couples (12\%) was primarily rural dwelling and under 40 years of age. 
TABLE 1 | Demographics and characteristics of survivors and partners ( $n=49$ couples).

\begin{tabular}{|c|c|c|c|c|c|}
\hline $\begin{array}{l}\text { Participant } \\
\text { characteristics }\end{array}$ & $\begin{array}{l}\text { Survivors } \\
\begin{array}{c}M \pm S D \text { or } \\
n(\%)\end{array}\end{array}$ & $\begin{array}{c}\text { Partner } \\
M \pm \text { SD or } \\
n(\%)\end{array}$ & $\begin{array}{c}t \\
\text { statistic }\end{array}$ & $\begin{array}{c}\text { Cohen's } \\
\text { d }\end{array}$ & Correlation \\
\hline Age (years) & $43.5 \pm 9.0$ & $43.9 \pm 9.7$ & -0.43 & & $0.79 * * *$ \\
\hline Sex (\% female) & 34 (69\%) & 16 (33\%) & & & \\
\hline Race (\% white) & 44 (90\%) & 40 (82\%) & & & \\
\hline $\begin{array}{l}\text { Ethnicity } \\
\text { (\% Hispanic) }\end{array}$ & $6(12 \%)$ & $6(12 \%)$ & & & \\
\hline $\begin{array}{l}\text { Education } \\
\text { (\% completed } \\
\text { college) }\end{array}$ & 36 (74\%) & 29 (59\%) & & & \\
\hline $\begin{array}{l}\text { Employment } \\
\text { (\% employed) }\end{array}$ & $30(61 \%)$ & 37 (76\%) & & & \\
\hline $\begin{array}{l}\text { Residence (\% } \\
\text { rural location) }\end{array}$ & 22 (45\%) & - & & & \\
\hline $\begin{array}{l}\text { Length of co- } \\
\text { residence (years) }\end{array}$ & $16.6 \pm 9.9$ & - & & & \\
\hline $\begin{array}{l}\text { Years since } \\
\text { diagnosis }\end{array}$ & $2.2 \pm 0.6$ & - & & & \\
\hline $\begin{array}{l}\text { Depressive } \\
\text { symptoms (0-60) }\end{array}$ & $15.5 \pm 11.3$ & $12.6 \pm 10.2$ & 1.49 & 0.22 & 0.22 \\
\hline $\begin{array}{l}\text { Active } \\
\text { engagement } \\
(0-20)\end{array}$ & $13.4 \pm 4.7$ & $13.2 \pm 3.8$ & 0.26 & 0.04 & $0.30 *$ \\
\hline $\begin{array}{l}\text { Protective } \\
\text { buffering (0-24) }\end{array}$ & $9.2 \pm 4.9$ & $7.5 \pm 3.7$ & 1.91 & 0.29 & 0.02 \\
\hline
\end{tabular}

Differences between survivors and partners were examined using paired t-tests. Correlations represent paired samples correlations between survivors and partners. $* p<0.05$ and $* * * p<0.001$

Breast cancer was the most common diagnosis for survivors (20\%), followed by cervical/ovarian (13\%), colon (10\%), and renal $(10 \%)$.

\section{Differences in Depressive Symptoms, Active Engagement, and Protective Buffering by Role, Survivor Age Group, and Survivor Sex}

Table 1 includes comparisons by role (i.e., survivor versus partner) in depressive symptoms, active engagement, and protective buffering. On average, survivor depressive symptoms were $15.5(S D=11.3)$ with $37 \%$ of survivors at or above a score of 16 (clinical cut-off for further assessment). Partner depressive symptoms were, on average, $12.6(S D=10.2)$ with $27 \%$ of partners at or above a score of 16. Half of couples in the sample had at least one member meeting the clinical cut-off ( $17 \%$ of couples had both members). There were no significant differences found between survivors and partners on depressive symptoms, or in perceived active engagement and protective buffering. Depressive symptoms between survivors and partners were correlated at 0.22 , indicating some covariation. Reports of active engagement were similarly correlated within couples. However, survivor and partner reports of protective buffering showed little to no correlation.

Table 2 includes comparisons by survivor age group (aged $<40$ versus aged 40 and older) in depressive symptoms, active engagement, and protective buffering. There were no significant differences in survivor or partner depressive symptoms, active engagement, or protective buffering behaviors by age group. Although not statistically significant, medium effects suggest younger survivors were more likely to report higher levels of active engagement by their partner (Cohen's $d=0.50$ ) than midlife survivors; younger partners were more likely to report higher levels of active engagement by their survivor (Cohen's $d=0.55)$.

Table 3 includes comparisons by survivor sex in depressive symptoms, active engagement, and protective buffering. There were no significant differences in depressive symptoms by survivor sex for survivors or partners. Significant sex differences were found for survivor-reported active engagement and survivorreported protective buffering. Male survivors $(p<0.05$; Cohen's $d=0.57$ ) reported significantly higher active engagement by their partner than female survivors. Female survivors $(p<0.05$; Cohen's $d=-0.74$ ) reported significantly higher protective buffering by their partner than male survivors. No significant differences were found for partners.

\section{Moderating Role of Survivor Age on the Associations Between Active Engagement and Protective Buffering and Depressive Symptoms}

Table 4 includes the results of the moderation analysis using age as a continuous variable. One significant interaction was found. First, we found evidence of a moderated partner effect in that survivor age significantly moderated the association between the survivor's perception of protective buffering (in their partner) and partner depressive symptoms $[p<0.5$; ES $(r)=0.32]$. Older partners, whose survivors perceived them to engage in lower protective buffering, reported lower depressive symptoms. In contrast, younger partners, whose survivor perceived them to engage in lower protective buffering, reported higher depressive symptoms (Figure 1A). No significant moderation effects were found for survivor depressive symptoms.

\section{Moderating Role of Survivor Sex on the Associations Between Active Engagement and Protective Buffering and Depressive Symptoms}

Table 5 includes the results of the analysis exploring survivor sex as a moderator. Three significant interactions were found. First, we found evidence of a moderated actor effect in that survivor sex significantly moderated the association between survivor's report of protective buffering (by their partner) on survivor depressive symptoms $[p<0.05$; ES $(r)=0.39]$. Female survivors, who reported fewer depressive symptoms, were significantly more likely to report their partners engaging in low levels of protective buffering. Male survivors, who reported fewer depressive symptoms, were significantly more likely to report their partner engaging in high levels of protective buffering (Figure 1B).

Second, we found evidence of a moderated partner effect in that survivor sex significantly moderated the association 
TABLE 2 | Comparison of depressive symptoms, active engagement, and protective buffering by survivor age group ( $n=49$ survivors).

\begin{tabular}{|c|c|c|c|c|}
\hline Variable & $\begin{array}{c}\text { Young SVRs } \\
\text { (<40years old) } \\
\text { M } \pm \text { SD }\end{array}$ & $\begin{array}{c}\text { Midlife SVRs } \\
\text { (> 40years old) } \\
M \pm S D\end{array}$ & $t$ statistic & Cohen's d \\
\hline SVR depressive symptoms & $13.4 \pm 9.1$ & $16.6 \pm 12.2$ & -1.35 & -0.29 \\
\hline Partner depressive symptoms & $9.7 \pm 10.4$ & $13.9 \pm 9.9$ & -1.35 & -0.42 \\
\hline SVR active engagement & $15.0 \pm 3.6$ & $12.7 \pm 5.1$ & 1.68 & 0.50 \\
\hline Partner active engagement & $14.5 \pm 3.8$ & $12.5 \pm 3.6$ & 1.83 & 0.55 \\
\hline SVR protective buffering & $8.7 \pm 4.8$ & $9.7 \pm 5.0$ & -0.64 & -0.19 \\
\hline Partner protective buffering & $7.4 \pm 4.1$ & $7.2 \pm 3.8$ & 0.14 & 0.04 \\
\hline
\end{tabular}

SVR, survivor.

TABLE 3 | Comparison of depressive symptoms, active engagement, and protective buffering by survivor sex ( $n=49$ survivors).

\begin{tabular}{|c|c|c|c|c|}
\hline Variable & $\begin{array}{c}\text { Female SVRs } \\
\qquad M_{ \pm} S D\end{array}$ & $\begin{array}{c}\text { Male SVRs } \\
M_{ \pm} \text {SD }\end{array}$ & $t$ statistic & Cohen's $d$ \\
\hline SVR depressive symptoms & $16.3 \pm 11.7$ & $13.3 \pm 9.8$ & -0.86 & -0.27 \\
\hline Partner depressive symptoms & $12.1 \pm 7.8$ & $13.4 \pm 14.6$ & 0.313 & 0.13 \\
\hline SVR active engagement & $12.8 \pm 5.3$ & $14.4 \pm 2.6$ & $2.37 *$ & 0.57 \\
\hline Partner active engagement & $12.9 \pm 3.6$ & $13.9 \pm 4.3$ & 0.85 & 0.27 \\
\hline SVR protective buffering & $10.4 \pm 5.1$ & $6.9 \pm 3.6$ & $-2.37 *$ & -0.74 \\
\hline Partner protective buffering & $7.5 \pm 3.6$ & $6.8 \pm 4.3$ & -0.60 & -0.19 \\
\hline
\end{tabular}

SVR, survivor. $* p<0.05$.

between partner's report of protective buffering (by the survivor) on survivor depressive symptoms $[p<0.05$; ES $(r)=0.31]$. Female survivors, who reported fewer depressive symptoms, were significantly more likely to have partners, who perceived them (the survivor) as engaging less in protective buffering. Male survivors, who reported fewer depressive symptoms, were significantly more likely to have partners, who perceived them (the survivor) as engaging more in protective buffering (Figure 1C).

Third, we found evidence of another moderated partner effect in that survivor sex significantly moderated the association between survivor's report of active engagement (by their partner) on partner depressive symptoms $[p<0.01$; ES $(r)=0.40]$. The depressive symptoms reported by partners of female survivors (almost all men) had little to no association with how the female survivor perceived the active engagement of the partner. In contrast, partners of male survivors (almost all women) had more depressive symptoms when the male survivor reported them as engaging in more active engagement (Figure 1D).

\section{DISCUSSION}

This study set out to explore the moderating roles of survivor age and sex on the associations between active engagement and protective buffering and depressive symptoms among youngmidlife couples 1 to 3 years after diagnosis. Although this study was limited by sample size, there are several noteworthy findings to inform future work. First, we found that over a third of survivors and a quarter of partners experienced high enough depressive symptomatology 1 to 3 years post-diagnosis to require further clinical assessment. We found no significant differences in level of depressive symptoms between survivors and partners or by survivor age group or sex. Within couples, we found that half of couples had at least one member (17\% had both members) scoring above the clinical cut-off for further assessment. Second, although active engagement and protective buffering behaviors did not differ significantly between survivors and partners, we did find group differences by survivor sex. Male survivors reported significantly higher levels of active engagement by their partners than female survivors and female survivors reported significantly higher levels of protective buffering by their partners than male survivors. Finally, we found some evidence to suggest that survivor age and sex may play moderating roles between these behaviors and depressive symptoms. Older partners and female survivors appeared to experience more positive effects than younger partners and male survivors.

Consistent with previous research (Mitchell et al., 2013; Champion et al., 2014; Shapiro, 2018), this study found that some couples surviving cancer beyond the first year still experience depressive symptoms. In contrast to a study of 1,127 couples 3-8years post-diagnosis that reported $18-27 \%$ of survivors with likely clinical depression requiring further assessment, our study (using similar clinical cut-offs) found $37 \%$ of survivors and $27 \%$ of partners requiring further assessment (Champion et al., 2014). Even using a more conservative cut-off of 20 that has been found to have a more adequate sensitivityspecificity balance for depression (Vilagut et al., 2016), our sample had $29 \%$ of survivors and $23 \%$ of partners meeting 
TABLE 4 | Moderating role of survivor age on associations between active engagement and protective buffering and depressive symptoms ( $n=49$ couples).

\section{Variables}

Depressive symptoms

\begin{tabular}{lllll}
\hline \multicolumn{2}{c}{ SVRs } & \multicolumn{3}{c}{ Partners } \\
\cline { 1 - 2 } B (SE) & ES (r) & B (SE) & ES (r)
\end{tabular}

\begin{tabular}{|c|c|c|c|c|}
\hline \multicolumn{5}{|l|}{ Active engagement } \\
\hline SVR age & $0.18(0.19)$ & 0.14 & $0.11(0.18)$ & 0.09 \\
\hline SVR-reported active engagement & $-0.28(0.37)$ & 0.12 & $0.21(0.33)$ & 0.10 \\
\hline Partner-reported active engagement & $0.18(0.19)$ & 0.14 & $-0.08(0.42)$ & 0.03 \\
\hline SVR age*SVR-reported active engagement & $-0.03(0.04)$ & 0.11 & $-0.02(0.04)$ & 0.08 \\
\hline SVR age*Partner-reported active engagement & $0.05(0.05)$ & 0.17 & $-0.07(0.04)$ & 0.22 \\
\hline \multicolumn{5}{|l|}{ Protective buffering } \\
\hline SVR age & $0.20(0.17)$ & 0.19 & $0.06(0.16)$ & 0.06 \\
\hline SVR-reported protective buffering & $0.56(0.32)$ & 0.27 & $0.24(0.30)$ & 0.02 \\
\hline Partner-reported protective buffering & $0.34(0.45)$ & 0.12 & $0.74(0.42)$ & 0.28 \\
\hline SVR age*SVR-reported protective buffering & $0.02(0.04)$ & 0.09 & $0.08(0.04)^{*}$ & 0.32 \\
\hline SVR age*Partner-reported protective buffering & $0.01(0.05)$ & 0.02 & $0.07(0.04)$ & 0.25 \\
\hline
\end{tabular}

B, unstandardized coefficient; SVR, survivor. Survivor age was included as a continuous variable. Both survivor age and both dyadic management behavior variables were centered to create interaction terms. Higher scores on active engagement and protective buffering indicate higher levels of each behavior. Effect size $r=\sqrt{\frac{t^{2}}{\left(t^{2}+d f\right)}} \cdot * p<0.05$.

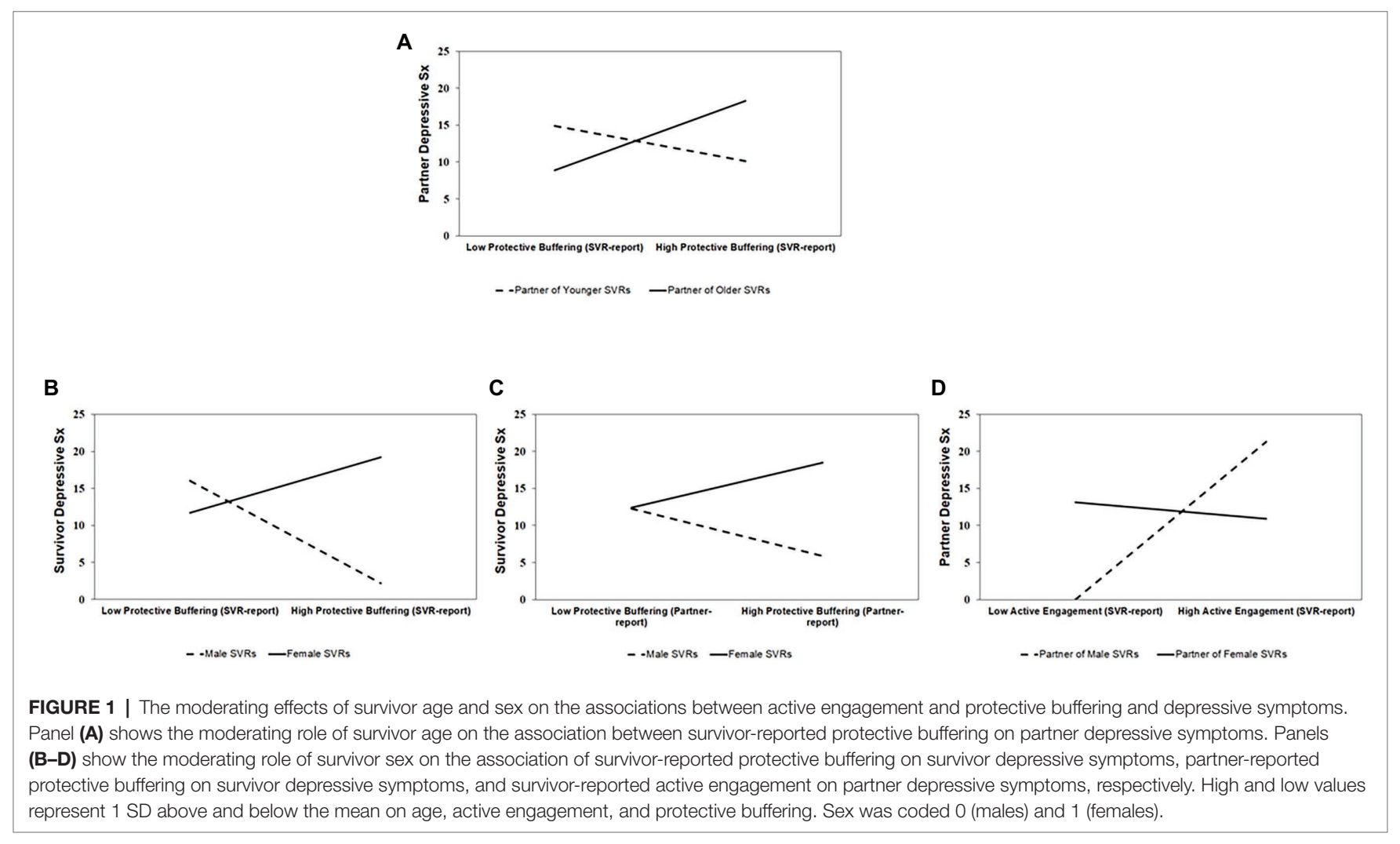

criteria. Moreover, $50 \%$ of our couples had one or both members meeting criteria. Unlike recent research on couples living with breast cancer, we did not find significant age-group differences (Acquati and Kayser, 2019) or survivor sex differences in depressive symptoms. As so little couple research in cancer has focused on cancers involving both sexes in young to mid-adulthood, replication of findings is needed before drawing strong conclusions about the lack of sex differences, though we acknowledge that $69 \%$ of survivors in our sample were female.

Despite the growing body of literature supporting the protective roles of open communication, supportive behaviors, and shared collaborative activities on the interdependent health 
TABLE 5 | Moderating role of survivor sex on associations between active engagement and protective buffering and depressive symptoms ( $n=49$ couples).

\begin{tabular}{|c|c|c|c|c|}
\hline \multirow[t]{3}{*}{ Variables } & \multicolumn{4}{|c|}{ Depressive symptoms } \\
\hline & \multicolumn{2}{|c|}{ SVRs } & \multicolumn{2}{|c|}{ Partners } \\
\hline & B (SE) & ES (r) & B (SE) & ES (r) \\
\hline \multicolumn{5}{|l|}{ Active engagement } \\
\hline $\begin{array}{l}\text { SVR sex } \\
\text { SVR-reported active } \\
\text { engagement }\end{array}$ & $\begin{array}{l}6.31(4.12) \\
1.65(1.20)\end{array}$ & $\begin{array}{l}0.05 \\
0.21\end{array}$ & $\begin{array}{c}3.75(3.62) \\
2.78(1.01)^{* *}\end{array}$ & $\begin{array}{l}0.16 \\
0.39\end{array}$ \\
\hline $\begin{array}{l}\text { Partner-reported active } \\
\text { engagement }\end{array}$ & $0.23(0.72)$ & 0.05 & $-0.44(0.62)$ & 0.11 \\
\hline $\begin{array}{l}\text { SVR sex*SVR-reported } \\
\text { active engagement }\end{array}$ & $-2.07(1.26)$ & 0.25 & $-3.01(1.07)^{* *}$ & 0.40 \\
\hline $\begin{array}{l}\text { SVR sex*Partner-reported } \\
\text { active engagement }\end{array}$ & $-0.25(0.91)$ & 0.04 & $0.60(0.79)$ & 0.01 \\
\hline \multicolumn{5}{|l|}{ Protective buffering } \\
\hline SVR sex & $6.36(3.70)$ & 0.27 & $-2.13(3.88)$ & 0.09 \\
\hline $\begin{array}{l}\text { SVR-reported protective } \\
\text { buffering }\end{array}$ & $-1.40(0.75)$ & 0.29 & $0.24(0.83)$ & 0.05 \\
\hline $\begin{array}{l}\text { Partner-reported protective } \\
\text { buffering }\end{array}$ & $-0.83(0.60)$ & 0.22 & $0.92(0.71)$ & 0.21 \\
\hline $\begin{array}{l}\text { SVR sex*SVR-reported } \\
\text { protective buffering }\end{array}$ & $2.16(0.83)^{*}$ & 0.39 & $-0.08(0.91)$ & 0.01 \\
\hline $\begin{array}{l}\text { SVR sex*Partner-reported } \\
\text { protective buffering }\end{array}$ & $1.63(0.80)^{*}$ & 0.31 & $-0.86(0.91)$ & 0.15 \\
\hline
\end{tabular}

B, unstandardized coefficient; SVR, survivor. Survivor sex was coded 0 (male) and 1 (female). Both dyadic management behavior variables were centered to create interaction terms. Higher scores on active engagement and protective buffering indicate higher levels of each behavior. Effect size $r=\sqrt{\frac{t^{2}}{\left(t^{2}+d f\right)}} \cdot * p<0.05$ and $* * p<0.01$.

of the dyad (Berg and Upchurch, 2007; Berg et al., 2008; Falconier et al., 2015; Regan et al., 2015; Traa et al., 2015; Shaffer et al., 2016; Lyons and Lee, 2018; Streck et al., 2020; Stefanut et al., 2021), few studies have explicitly examined whether such beneficial effects vary by survivor age or sex. Our findings suggest that the beneficial effects of such behaviors may not be universal.

Specifically, older partners (i.e., as age increased) experienced lower depressive symptoms when the survivor reported them as engaging in less protective buffering. Thus, partners, in our sample, more likely to be older (i.e., in midlife) than younger, benefitted from low levels of protective buffering. Yet, younger partners did not appear to benefit similarly in the current sample. Younger couples tend to be newer to their relationships with one another (as was true in our study) and may be less experienced in these types of positive communication skills and supportive behaviors than older couples (Berg and Upchurch, 2007), with recent evidence that younger partners engage in significantly higher levels of negative dyadic behaviors than midlife partners (Acquati and Kayser, 2019). The off-time nature of the cancer experience and unexpected role of care partner may be particularly challenging for younger-aged partners, who may be unsure of how to emotionally support the survivor over time and the appropriateness of balancing their own needs.
Relatedly, the social cognitive processing theory (Lepore and Revenson, 2007) purports that our psychological health is influenced by our ability to process and discuss traumatic events, such as a cancer diagnosis, with those who are closest to us. When attempts to discuss or communicate openly about the experience with one's partner or family member is perceived to be met with unsupportive responses or social constraints, the person attempting to share can be hindered in their ability to cognitively process the experience, leading to intrusive thoughts and cognitive avoidance, and ultimately higher depressive symptoms (Lepore and Revenson, 2007; Cohee et al., 2017). Several items on the protective buffering measure are similar to those on measures of social constraint by one's partner (e.g., "my partner tries to hide worries about me," "my partner tries to act as if nothing is the matter," "my partner just waves my worries aside," and "my partner does everything to prevent me from thinking about my cancer"). Thus, when young survivors in the current sample reported high levels of what could be considered social constraint behaviors by their partners, partners reported low levels of depressive symptoms. It is possible that younger partners are experiencing some benefit from not engaging in open communication and discussion about the cancer experience either because they see their supportive role as one of protection through denial and distraction (Manne et al., 2004a, 2005, 2015; Lepore and Revenson, 2007), because they lack skills and confidence to openly communicate, or such supportive and open communication about their partner's cancer may be too emotionally draining for them (Ernst et al., 2017; Crangle et al., 2020; Reblin et al., 2020). It is also possible they perceived social constraints from the survivor. All of which highlight the complexity of communication and support within couples experiencing illness and need for couple-based interventions to facilitate these skills of sharing and reciprocal disclosure, particularly for those in care partner and supportive roles, who often feel guilty about expressing their own needs and challenges (Spillers et al., 2008; Yeung et al., 2018).

However, given the cross-sectional nature of the study, it is also possible that younger partners with high levels of depressive symptoms were more likely to be perceived by the younger survivor as engaging in less protective buffering. Younger couples may not want or be unsure of how to openly discuss due to their earlier stage in life and early stage of the relationship, and may be more prone to want to move on and avoid discussion or believe this is the positive thing to do (Pistrang and Barker, 2005). Clearly, much more research is needed to untangle these effects and how they unfold for the younger couple over time.

Similarly, we found differential effects by survivor sex. Female survivors, who reported few depressive symptoms, were either significantly more likely to report their partners engaging in lower levels of protective buffering or were more likely to have partners who perceived them (the survivor) as engaging less in protective buffering. The same beneficial effect was not observed for male survivors. This raises the potential of how male survivors are interpreting the meaning and value of protective buffering behaviors (by themselves and their partners) 
and whether we are detecting engendered effects about the relational nature of women's identities versus the social expectations of masculinity that may drive patterns of distraction and denial/avoidance by men in illness contexts (Manne et al., 2005, 2015; Pistrang and Barker, 2005; Badr and Carmack Taylor, 2006; Mahalik and Dagirmanjian, 2019). Men, across races, ethnicities, and the adult life span, have been found to seek help for mental health and depression less than women (Addis and Mahalik, 2003). Indeed, recent research suggested that husbands of women with breast cancer, who highly endorsed masculine strength, experienced significantly higher levels of guilt when they did seek help and those husbands who engaged in protective buffering experienced significantly less guilt (Yeung et al., 2018).

Finally, partners of male survivors (all women but one) reported higher levels of depressive symptoms when the survivor perceived them to be engaged in high levels of active engagement. It is unclear if this indicates that partners experiencing higher levels of depressive symptoms were prompted to engage in more open communication to deal with what they were experiencing and as a way to process and seek support rather than the engagement in open communication leading to depressive symptoms. Though social cognitive processing theory would suggest that if those active engagement behaviors, by the predominantly female partners in the study, were met with social constraint, they could lead to poor mental health over time (Lepore and Revenson, 2007).

It is unfortunately not possible to untangle the full story behind the effects observed in the current study, nor tease apart what may well be an intersection of age and sex in how styles of communication and ability to openly communicate, receive the communication and reciprocally disclose are interpreted and used. Social constraints arise not only from the environment and social context present, but are also strongly driven by the interpretation of the person disclosing (Lepore and Revenson, 2007), which may not be readily understood by the person hearing that disclosure. Although much of the work around couple communication in cancer and other illnesses has focused on the survivor's disclosures and the supportive/unsupportive behaviors and responses of their partner, a more balanced approach to the transactions within couples and partner's disclosures may lead to a more shared understanding of the positive ways to communicate and support, promote reciprocal disclosures, empathetic listening, and perspective-taking by both. In addition to the potential roles of age and sex in dyadic behaviors, the family care literature highlights some of the misplaced assumptions and guilt care partners can feel in voicing their own needs and challenges, particularly for male and younger partners (Spillers et al., 2008; Yeung et al., 2018). This guilt and perceived role expectations to remain positive and focus solely on the needs of their partner with illness may hinder the couple from achieving healthy, long-term communication, and mutually supportive skills and strategies. Research has consistently found that care partners also experience negative outcomes and poor health as in the current study (Kent et al., 2016; Kim et al., 2016; Shaffer et al., 2016), sometimes at significantly higher levels than the person with illness (Lee and Lyons, 2019).

\section{Limitations}

There are several important limitations to the current work. First, the sample is small and cross-sectional. This not only prevents us from drawing any conclusions about directionality of associations (though theory strongly guided our research questions), but we are underpowered to adequately test moderation and draw strong conclusions from our findings. We tried to ameliorate the small sample by focusing only on those results with medium-large effect sizes and using age as a continuous variable in the moderation analyses (Altman and Royston, 2006), but call for replication of our results in larger, more diverse samples. Second, our homogeneous sample also lacked racial diversity and included only one same-sex couple preventing us from examining these associations within groups of couples. Thus, it is possible that in larger, more diverse samples or samples focused solely on couples under-represented in couple research, we may uncover other contexts where the benefits of dyadic behaviors are not present or are unclear. Finally, we did not limit our sample to a certain type of cancer or group of cancers as we deliberately wanted to explore survivor sex separate from role (i.e., survivor versus partner). We acknowledge the heterogeneity that this introduces, but given that our guiding theory purports to be relevant for most illness contexts, we believe this inclusive criterion has provided salient information. Finally, we did not include a measure of collaborative illness management in the study so cannot compare the more non-verbal ways couples collaborate and support one another in the context of illness.

\section{Strengths and Implications}

Despite these limitations, this population-based study contributes to the field of dyadic science in cancer in several ways. First, our results question the universal benefits of more open communication and the potentially salient roles of survivor age and sex. It is our hope that these results will guide future directions for more deliberate research to examine these processes within larger samples over time in more nuanced ways. Moreover, to truly examine the role of age in dyadic processes and behaviors, samples should purposely include couples across the entire adult life span (Acquati and Kayser, 2019). Second, we believe our inclusion of more than one cancer increases the generalizability of our findings and prompts further work to tease apart the intersectionality of sex, age, and role. Third, our purposeful focus and recruitment of couples under the age of 40 1-3 years post-diagnosis from both rural and urban areas adds to the emerging body of research on the ongoing challenges and experiences of these overlooked couples. Finally, our findings highlight the ongoing emotional strain experienced by some young and midlife couples surviving cancer after the first year of diagnosis.

We see several implications from this work. Examining the roles of sex and age within diverse groups of couples is needed to understand how dyadic processes hold up in different cultures and contexts across the life span. Moreover, the role of family around the couple is often neglected from the dyadic science of illness, yet the family context and family relationships can play important (albeit different) roles for couples across the 
life span and in different cultures (Carter et al., 2010; Jeong et al., 2018; Bonds Johnson et al., 2021). We have found familial support to be an important factor for dyadic outcomes in much of our research (Lyons and Lee, 2018; Lyons et al., 2021, 2022). Combining dyadic theories of health and illness with more specific theories of social cognitive processing and communication may lead to more balanced and nuanced ways to design couple-based interventions that not only facilitate communication skills and non-verbal collaboration, but also acknowledge the challenges for care partners, the readiness to share and listen within the couple, and times when other supporters beyond the couple may be beneficial. Furthermore, supportive and open communication is just one way that couples collaborate and manage cancer together. The TDIM purports that dyadic illness management behaviors comprise of not just open communication, but also supportive behaviors to survivor and care partner, shared health behaviors, and collaborative illness and care management behaviors (Lyons and Lee, 2018; Lyons et al., 2022). Thus, multicomponent couple-based interventions and approaches may be optimal and provide maximum tailoring to the specific needs and challenges of couples.

Clearly, one size does not fit all couples and challenges around communication and support may change with the cancer trajectory, stage of cancer, place in the life span, stage of the relationship, the sex of both survivor and partner, and their role in the relationship. Younger couples may be particularly in need of interventions to learn to cope with stress compared to older couples who may have already weathered challenges together. Similarly, some men (particularly in partner roles) may benefit from more nuanced approaches to open communication that acknowledge the role of more traditional masculine identities and potential lack of skill and experience with disclosure and open communication. Research that delves deeper into the ways couples communicate and collaborate and identifies couples who are most vulnerable and unable to support one another is needed. Recent longitudinal work examining communication and relationship outcomes using ecological momentary assessment is a noteworthy example (Langer et al., 2018). The dyadic science of illness and health has led to important and relevant theories and knowledge and directly informed effective couple-based interventions ( $\mathrm{Li}$ and Loke, 2014; Winters-Stone et al., 2016; Langer et al., 2018; Hornbuckle et al., 2021; Reese et al., 2021). This study not

\section{REFERENCES}

Acitelli, L. K., and Badr, H. J. (2005). "My illness or our illness? attending to the relationship when one partner is ill," in Couples Coping with Stress: Emerging Perspectives on Dyadic Coping. eds. T. A. Revenson, K. Kayser and G. Bodenmann (Washington, DC: American Psychological Association), 121-136.

Acquati, C., and Kayser, K. (2019). Dyadic coping across the lifespan: A comparison between younger and middle-aged couples with breast cancer. Front. Psychol. 10:404. doi: 10.3389/fpsyg.2019.00404

Addis, M. E., and Mahalik, J. R. (2003). Men, masculinity, and the contexts of help-seeking. Am. Psychol. 58, 5-14. doi: 10.1037/0003-066X.58.1.5

Altman, D. G., and Royston, P. (2006). The cost of dichotomising continuous variables. Br. Med. J. 332:1080. doi: 10.1136/bmj.332.7549.1080 only supports that work but prompts further exploration of when, why, and for whom these processes do not lead to beneficial outcomes.

\section{DATA AVAILABILITY STATEMENT}

The raw data supporting the conclusions of this article will be made available by the authors, without undue reservation.

\section{ETHICS STATEMENT}

The studies involving human participants were reviewed and approved by the Institutional Review Board at Oregon Health and Science University (e\#15498). The patients/participants provided their written informed consent to participate in this study.

\section{AUTHOR CONTRIBUTIONS}

$\mathrm{KL}$ and $\mathrm{BH}-\mathrm{L}$ contributed to the conceptualization and design of the study. JG contributed to the conceptualization of the study. BL contributed to the data management and preliminary analysis. GD contributed to the preliminary analysis. KL wrote the first draft of the manuscript. KL and JG wrote sections of the manuscript. All authors contributed to the manuscript revision, read, and approved the submitted version.

\section{FUNDING}

This work was generously supported by the Betty Gray Foundation, Oregon.

\section{ACKNOWLEDGMENTS}

The authors are sincerely grateful to the couples who participated and for the support of the staff at the Oregon State Cancer Registry (OSCaR). We are also grateful to Susan Rosenkranz, Wafaa Bin Ali, and Mashael Dewan for their roles in recruitment and data collection.

American Cancer Society (2021). Cancer Treatment and Survivorship Facts and Figures 2019-2021. Atlanta: American Cancer Society.

American Psychological Association (2019). Stress in America: Stress and Current Events (Online). Available at: https:/www.apa.org/news/press/releases/ stress/2019/stress-america-2019.pdf (Accessed January 20, 2020).

Badr, H., and Acitelli, L. K. (2017). Re-thinking dyadic coping in the context of chronic illness. Curr. Opin. Psychol. 13, 44-48. doi: 10.1016/j.copsyc.2016.03.001

Badr, H., and Carmack Taylor, C. L. (2006). Social constraints and spousal communication in lung cancer. Psycho-Oncology 15, 673-683. doi: 10.1002/ pon.996

Barnett, M., Mcdonnell, G., Derosa, A., Schuler, T., Philip, E., Peterson, L., et al. (2016). Psychosocial outcomes and interventions among cancer survivors diagnosed during adolescence and young adulthood (AYA): a systematic review. J. Cancer Surviv. 10, 814-831. doi: 10.1007/s11764-016-0527-6 
Beekman, A. T. F., Deeg, D. J. H., Van Limbeek, J., Braam, A. W., De Vries, M. Z., and Van Tilburg, W. (1997). Criterion validity of the Center for Epidemiological Studies Depression Scale (CES-D): results from a community-based sample of older subjects in the Netherlands. Psychol. Med. 27, 231-235. doi: 10.1017/ S0033291796003510

Berg, C. A., and Upchurch, R. (2007). A developmental-contextual model of couples coping with chronic illness across the adult life span. Psychol. Bull. 133, 920-954. doi: 10.1037/0033-2909.133.6.920

Berg, C. A., Wiebe, D. J., Butner, J., Bloor, L., Bradstreet, C., Upchurch, R., et al. (2008). Collaborative coping and daily mood in couples dealing with prostate cancer. Psychol. Aging 23, 505-516. doi: 10.1037/a0012687

Bodenmann, G. (1997). Dyadic coping - a systematic-transactional view of stress and coping among couples: theory and empirical findings. Eur. Rev. Appl. Psychol. 47, 137-140.

Bonds Johnson, K., Brewster, G. S., Cicero, E., Hepburn, K., Clevenger, C. K., Daniel, G., et al. (2021). Promoting caregiver mastery in black American dementia caregivers. Gerontologist. doi: 10.1093/geront/gnab147, [Epub Ahead of Print].

Borstelmann, N. A., Rosenberg, S. M., Ruddy, K. J., Tamimi, R. M., Gelber, S., Schapira, L., et al. (2015). Partner support and anxiety in young women with breast cancer. Psycho-Oncology 24, 1679-1685. doi: 10.1002/pon.3780

Buunk, B. P., Berkhuysen, M. A., Sanderman, R., Nieuwland, W., and Ranchor, A. V. (1996). Actieve betrokkenheid, beschermend bufferen en overbescherming: Meetinstrumenten voor de role van de partner bij hartrevalidatie [The role of the partner in heart disease: active engagement, protective buffering, and overprotection]. Gedrag. Gezondheid. 24, 304-313.

Carter, J. H., Lyons, K. S., Stewart, B. J., Archbold, P. G., and Scobee, R. (2010). Does age make a difference in caregiver strain? Comparison of young versus older caregivers in early-stage Parkinson's disease. Mov. Disord. 25, 724-730. doi: $10.1002 / \mathrm{mds} .22888$

Champion, V. L., Wagner, L. I., Monahan, P. O., Daggy, J., Smith, L., Cohee, A., et al. (2014). Comparison of younger and older breast cancer survivors and age matched controls on specific and overall quality of life. Cancer 120, 2237-2246. doi: 10.1002/cncr.28737

Chan, R. J., Nekhlyudov, L., Duijts, S. F. A., Hudson, S. V., Jones, J. M., Keogh, J., et al. (2021). Future research in cancer survivorship. J. Cancer Surv. 15, 659-667. doi: 10.1007/s11764-021-01102-x

Cohee, A. A., Adams, R. N., Fife, B. L., Von Ah, D. M., Monahan, P. O., Zoppi, K. A., et al. (2017). The relationship between depressive symptoms and social cognitive processing in partners of long-term breast cancer survivors. Oncol. Nurs. Forum 44, 44-51. doi: 10.1188/17.ONF.44-51

Collaço, N., Wagland, R., Alexis, O., Gavin, A., Glaser, A., and Watson, E. K. (2019). The challenges on the family unit faced by younger couples affected by prostate cancer: A qualitative study. Psycho-Oncology 28, 329-335. doi: 10.1002/pon.4944

Corney, R., Puthussery, S., and Swinglehurst, J. (2016). Couple relationships in families with dependent children after a diagnosis of maternal breast cancer in the United Kingdom: perspectives from mothers and fathers. J. Psychosoc. Oncol. 34, 413-431. doi: 10.1080/07347332.2016.1199080

Costanzo, E. S., Ryff, C. D., and Singer, B. H. (2009). Psychosocial adjustment among cancer survivors: findings from a national survey of health and well-being. Health Psychol. 28, 147-156. doi: 10.1037/a0013221

Coyne, J. C., and Smith, D. A. (1991). Couples coping with a myocardial infarction: A contextual perspective on wives' distress. J. Pers. Soc. Psychol. 61, 404-412. doi: 10.1037/0022-3514.61.3.404

Crangle, C. J., Torbit, L. A., Ferguson, S. E., and Har, T. L. (2020). Dyadic coping mediates the effects of attachment on quality of life among couples facing ovarian cancer. J. Behav. Med. 43, 564-575. doi: 10.1007/s10865-01900096-3

Dewan, M. F., Gorman, J. R., Hayes-Lattin, B., and Lyons, K. S. (2021). Open communication and physical intimacy in young-midlife couples surviving cancer. Oncol. Nurs. Forum 48, 669-679. doi: 10.1188/21.onf.669-679

Ernst, J., Hinz, A., Niederwieser, D., Döhner, H., Hönig, K., Vogelhuber, M., et al. (2017). Dyadic coping of patients with hematologic malignancies and their partners and its relation to quality of life - a longitudinal study. Leuk. Lymphoma 58, 655-665. doi: 10.1080/10428194.2016.1194983

Falconier, M. K., Jackson, J. B., Hilpert, P., and Bodenmann, G. (2015). Dyadic coping and relationship satisfaction: a meta-analysis. Clin. Psychol. Rev. 42, 28-46. doi: 10.1016/j.cpr.2015.07.002
Falconier, M. K., and Kuhn, R. (2019). Dyadic coping in couples: A conceptual integration and a review of the empirical literature. Front. Psychol. 10:571. doi: 10.3389/fpsyg.2019.00571

Garcia, R. L., Kenny, D. A., and Ledermann, T. (2015). Moderation in the actor-partner interdependence model. Pers. Relationship 22, 8-29. doi: 10.1111/ pere. 12060

Gorman, J. R., Smith, E., Drizin, J. H., Lyons, K. S., and Harvey, S. M. (2020). Navigating sexual health in cancer survivorship: A dyadic perspective. Support. Care Cancer 28, 5429-5439. doi: 10.1007/s00520-020-05396-y

Hagedoorn, M., Kuijer, R. G., Wobbes, T., and Sanderman, R. (2000). Marital satisfaction in patients with cancer: does support from intimate partners benefit those who need it the most? Health Psychol. 19, 274-282. doi: 10.1037/0278-6133.19.3.274

Hagedoorn, M., Sanderman, R., Coyne, J. C., Bolks, H. N., and Tuinstra, J. (2008). Distress in couples coping with cancer: A meta-analysis and critical review of role and gender effects. Psychol. Bull. 134, 1-30. doi: 10.1037/00332909.134.1.1

Harden, J. K., Northouse, L., and Mood, D. (2006). Qualitative analysis of couples' experience with prostate cancer by age cohort. Cancer Nurs. 29, 367-377. doi: 10.1097/00002820-200609000-00004

Hareven, T. K. (1994). Aging and generational relations: A historical and life course perspective. Annu. Rev. Sociol. 20, 437-461. doi: 10.1146/annurev. so.20.080194.002253

Hinnen, C., Hagedoorn, M., Sanderman, R., and Ranchor, A. V. (2007). The role of distress, neuroticism and time since diagnosis in explaining support behaviors in partners of women with breast cancer: results of a longitudinal analysis. Psycho-Oncology 16, 913-919. doi: 10.1002/pon.1153

Hornbuckle, L. M., Rauer, A., Winters-Stone, K. M., Springer, C., Jones, C. S., and Toth, L. P. (2021). Better together? A pilot study of romantic partner influence on exercise adherence and cardiometabolic risk in African-American couples. J. Racial Ethn. Health Dis. 8, 1492-1504. doi: 10.1007/s40615-020-00912-6 Howlader, N., Noone, A. M., Krapcho, M., Miller, D., Brest, A., Yu, M., et al. (2019). SEER Cancer Statistics Review, 1975-2016 Based on November 2018 SEER Data Submission (Online). Bethesda, MD: National Cancer Institute. Available at: https://seer.cancer.gov/archive/csr/1975_2016/ (Accessed August 2021).

Hydeman, J. A., Uwazurike, O. C., Adeyemi, E. I., and Beaupin, L. K. (2019). Survivorship needs of adolescent and young adult cancer survivors: a concept mapping analysis. J. Cancer Surviv. 13, 34-42. doi: 10.1007/ s11764-018-0725-5

Jeong, A., Shin, D., Park, J. H., and Park, K. (2018). What we talk about when we talk about caregiving: The distribution of roles in cancer patient caregiving in a family-oriented culture. Cancer Res. Treat. 51, 141-149. doi: $10.4143 /$ crt.2017.557

Kent, E. E., Rowland, J. H., Northouse, L., Litzelman, K., Chou, W. S. Shelburne, N., et al. (2016). Caring for caregiver and patients: research and clinical priorities for informal cancer caregiving. Cancer 122, 1987-1995. doi: $10.1002 /$ cncr.29939

Kiecolt-Glaser, J. K., and Newton, T. L. (2001). Marriage and health: his and hers. Psychol. Bull. 127, 472-503. doi: 10.1037/0033-2909.127.4.472

Kim, H. J., Sun, V., Raz, D. J., Williams, A. C., Fujinami, R., Reckamp, K., et al. (2016). The impact of lung cancer surgery on quality of life trajectories in patients and family caregivers. Lung Cancer 101, 35-39. doi: 10.1016/j. lungcan.2016.08.011

Langer, S., Lehane, C., and Yi, J. (2017). Patient and caregiver adjustment to hematopoietic stem cell transplantation: a systematic review of dyad-based studies. Curr. Hematol. Malig. Rep. 12, 324-334. doi: 10.1007/s11899-017-0391-0

Langer, S. L., Romano, J. M., Todd, M., Strauman, T. J., Keefe, F. J., Syrjala, K. L., et al. (2018). Links between communication and relationship satisfaction among patients with cancer and their spouses: results of a fourteen-day smartphone-based ecological momentary assessment study. Front. Psychol. 9:1843. doi: 10.3389/fpsyg.2018.01843

Lee, C. S., and Lyons, K. S. (2019). Patterns, relevance and predictors of dyadic mental health over time in lung cancer. Psycho. Oncology 28, 1721-1727. doi: $10.1002 /$ pon.5153

Lee, C. S., Sethares, K., Thompson, J. H., Faulkner, K. M., Aarons, E., and Lyons, K. S. (2020). Patterns of heart failure dyadic illness management: The important role of gender. J. Cardiovasc. Nurs. 35, 416-422. doi: 10.1097/ JCN.0000000000000695 
Lepore, S. J., and Revenson, T. A. (2007). Social constraints on disclosure and adjustment to cancer. Soc. Personal. Psychol. Compass 1, 313-333. doi: 10.1111/j.1751-9004.2007.00013.x

Li, Q., and Loke, A. Y. (2014). A systematic review of spousal couple-based intervention studies for couples coping with cancer: direction for the development of interventions. Psycho-Oncology 23, 731-739. doi: 10.1002/ pon. 3535

Lyons, K. S., Bennett, J. A., Nail, L. M., Fromme, E. K., Dieckmann, N., and Sayer, A. G. (2014). The role of patient pain and physical function on depressive symptoms in couples with lung cancer: A longitudinal dyadic analysis. J. Fam. Psychol. 28, 692-700. doi: 10.1037/fam0000017

Lyons, K. S., Flatley, C., Gorman, J. R., Hanan, D. M., and Hayes-Lattin, B. (2022). Challenges experienced and resources identified by young to midlife couples 1-3 years post-cancer diagnosis. Psycho-Oncology 31, 116-121. doi: 10.1002/pon. 5788

Lyons, K. S., Hiatt, S., Gelow, J. M., Auld, J., Mudd, J. O., Chien, C. V., et al. (2018). Depressive symptoms in couples living with heart failure: The role of congruent engagement in heart failure management. Aging Ment. Health 22, 1585-1591. doi: 10.1080/13607863.2017.1381945

Lyons, K. S., Hutton-Johnson, S., and Lee, C. S. (2021). The role of symptom appraisal, concealment and social support in optimizing dyadic mental health in heart failure. Aging Ment. Health 25, 734-741. doi: 10.1080/13607863. 2020.1711866

Lyons, K. S., and Lee, C. S. (2018). The theory of dyadic illness management. J. Fam. Nurs. 24, 8-28. doi: 10.1177/1074840717745669

Lyons, K. S., Miller, L. M., and Mccarthy, M. J. (2016a). The roles of dyadic appraisal and dyadic coping in couples with lung cancer. J. Fam. Nurs. 22, 493-514. doi: 10.1177/1074840716675976

Lyons, K. S., Sadowski, T., and Lee, C. S. (2020). The role of concealment and relationship quality on patient hospitalizations, care strain and depressive symptoms in heart failure dyads. Eur. J. Cardiovasc. Nurs. 19, 118-124. doi: $10.1177 / 1474515119863791$

Lyons, K. S., Winters-Stone, K. M., Bennett, J. A., and Beer, T. M. (2016b). The effects of partnered exercise on physical intimacy in couples coping with prostate cancer. Health Psychol. 35, 509-513. doi: 10.1037/hea0000287

Mahalik, J. R., and Dagirmanjian, F. R. (2019). Working-class men's constructions of help-seeking when feeling depressed or sad. Am. J. Mens Health 13:155798831985005. doi: 10.1177/1557988319850052

Manne, S. L., Kissane, D., Zaider, T., Kashy, D., Lee, D., Heckman, C., et al. (2015). Holding back, intimacy, and psychological and relationship outcomes among couples coping with prostate cancer. J. Fam. Psychol. 29, 708-719. doi: 10.1037/fam0000096

Manne, S., Ostroff, J., Rini, C., Fox, K., Goldstein, L., and Grana, G. (2004a). The interpersonal process model of intimacy: The role of self-disclosure, partner disclosure, and partner responsiveness in interactions between breast cancer patients and their partners. J. Fam. Psychol. 18, 589-599. doi: 10.1037/0893-3200.18.4.589

Manne, S., Ostroff, J., Sherman, M., Heyman, R. E., Ross, S., and Fox, K. (2004b). Couples' support-related communication, psychological distress, and relationship satisfaction among women with early stage breast cancer. $J$. Consult. Clin. Psychol. 72, 660-670. doi: 10.1037/0022-006X.72.4.660

Manne, S., Ostroff, J., Winkel, G., Grana, G., and Fox, K. (2005). Partner unsupportive responses, avoidant coping, and distress among women with early stage breast cancer: patient and partner perspectives. Health Psychol. 24, 635-641. doi: 10.1037/0278-6133.24.6.635

Meier, F., Cairo Notari, S., Bodenmann, G., Revenson, T. A., and Favez, N. (2019). We are in this together - Aren't we congruence of common dyadic coping and psychological distress of couples facing breast cancer. Psycho. Oncol. 28, 2374-2381. doi: 10.1002/pon.5238

Mitchell, A. J., Ferguson, D. W., Gill, J., Paul, J., and Symonds, P. (2013). Depression and anxiety in long-term cancer survivors compared with spouses and healthy controls: a systematic review and meta-analysis. Lancet Oncol. 14, 721-732. doi: 10.1016/S1470-2045(13)70244-4

Neugarten, B. L. (1979). Time, age, and the life cycle. Am. J. Psychiatr. 136, 887-894. doi: 10.1176/ajp.136.7.887

Pistrang, N., and Barker, C. (2005). "How partbers talk in times of stress: A process analysis approach," in Couples Coping With Stress: Emerging Perspectives on Dyadic Coping. eds. T. A. Revenson, K. Kayser and G. Bodenmann (Washington, DC: American Psychological Association), 97-119.
Radloff, L. S. (1977). The CES-D scale: A self-report depression scale for research in the general population. Appl. Psychol. Meas. 1, 385-401. doi: $10.1177 / 014662167700100306$

Reblin, M., Otto, A. K., Ketcher, D., Vadaparampil, S. T., Ellington, L., and Heyman, R. E. (2020). In-home conversations of couples with advanced cancer: support has its costs. Psycho. Oncol. 29, 1280-1287. doi: 10.1002/ pon. 5416

Reese, J. B., Sorice, K., Pollard, W., Handorf, E., Beach, M. C., Daly, M. B., et al. (2021). Efficacy of a multimedia intervention in enhancing breast cancer patients' clinical communication about sexual health: results of a randomized controlled trial. Psycho. Oncol. 30, 681-690. doi: 10.1002/ pon. 5613

Regan, T. W., Lambert, S. D., Kelly, B., Falconier, M., Kissane, D., and Levesque, J. V. (2015). Couples coping with cancer: exploration of theoretical frameworks from dyadic studies. Psycho-Oncology 24, 1605-1617. doi: $10.1002 /$ pon.3854

Revenson, T. A., Kayser, K., and Bodenmann, G. (eds.) (2005). Couples Coping with Stress: Emerging Perspectives on Dyadic Coping. Washington, DC: American Psychological Association.

Rottmann, N., Hansen, D. G., Hagedoorn, M., Larsen, P. V., Nicolaisen, A., Bidstrup, P. E., et al. (2016). Depressive symptom trajectories in women affected by breast cancer and their male partners: a nationwide prospective cohort study. J. Cancer Surviv. 10, 915-926. doi: 10.1007/s11764-0160538-3

Scott, A. R., Stooltzfus, K. C., Tchelebi, L. T., Trifiletti, D. M., Lehrer, E. J., Rao, P., et al. (2020). Trends in cancer incidence in US adolescents and young adults, 1973-2015. JAMA Net. Open 3:e2027738. doi: 10.1001/ jamanetworkopen.2020.27738

Shaffer, K. M., Kim, Y., and Carver, C. S. (2016). Physical and mental health trajectories of cancer patients and caregivers across the year post-diagnosis: a dyadic investigation. Psychol. Health 31, 655-674. doi: 10.1080/08870446.2015. 1131826

Shapiro, C. L. (2018). Cancer survivorship. N. Engl. J. Med. 379, 2438-2450. doi: 10.1056/NEJMra1712502

Smith, A. W., Seibel, N. L., Lewis, D. R., and Al, E. (2016). Next steps for adolescent and young adult oncology workshop: An update on progress and recommendations for the future. Cancer 122, 988-999. doi: 10.1002/ cncr. 29870

Spillers, R. L., Wellisch, D. K., Kim, Y., Matthews, B. A., and Baker, F. (2008). Family caregivers and guilt in the context of cancer care. Psychosomatics 49, 511-519. doi: 10.1176/appi.psy.49.6.511

Stefanut, A. M., Vintila, M., and Tudorel, O. I. (2021). The relationship of dyadic coping with emotional functioning and quality of the relationship in couples facing cancer - A meta-analysis. Front. Psychol. 11:594015. doi: 10.3389/fpsyg.2020.594015

Streck, B. P., Wardell, D. W., Lobiondo-Wood, G., and Beauchamp, J. E. S. (2020). Interdependence of physical and psychological morbidity among patients with cancer and family caregivers: review of the literature. PsychoOncology 29, 974-989. doi: 10.1002/pon.5382

Traa, M. J., De Vries, J., Bodenmann, G., and Den Oudsten, B. L. (2015). Dyadic coping and relationship functioning in couples coping with cancer: a systematic review. Br. Psychol. Soc. 20, 85-114. doi: 10.1111/bjhp. 12094

Vilagut, G., Forero, C. G., Barbaglia, G., and Alonso, J. (2016). Screening for depression in the general population with the Center for Epidemiologic Studies Depression (CES-D): A systematic review with meta-analysis. PLoS One 11:e0155431. doi: 10.1371/journal.pone.0155431

Wilson, S. J., Pengb, J., Andridgeb, R., Jaremkac, L. M., Fagundesd, C. P., Malarkeye, W. B., et al. (2020). For better and worse? The roles of closeness, marital behavior, and age in spouses' cardio metabolic similarity. Psychoneuroendocrinology 120:104777. doi: 10.1016/j.psyneuen.2020. 104777

Winters-Stone, K. M., Lyons, K. S., Dobek, J., Dieckmann, N. F., Bennett, J. A., Nail, L., et al. (2016). Benefits of partnered strength training for prostate cancer survivors and spouses: results from a randomized controlled trial of the exercising together project. J. Cancer Surviv. 10, 633-644. doi: 10.1007/ s11764-015-0509-0

Yeung, N. C. Y., Zhang, Y., Ji, L., Lu, G., and Lu, Q. (2018). Guilt among husband caregivers of Chinese women with breast cancer: The roles of 
male gender-role norm, caregiving burden and coping processes. Eur. J. Cancer Care 27:e12872. doi: 10.1111/ecc.12872

Conflict of Interest: The authors declare that the research was conducted in the absence of any commercial or financial relationships that could be construed as a potential conflict of interest.

Publisher's Note: All claims expressed in this article are solely those of the authors and do not necessarily represent those of their affiliated organizations, or those of the publisher, the editors and the reviewers. Any product that may be evaluated in this article, or claim that may be made by its manufacturer, is not guaranteed or endorsed by the publisher.

Copyright (c) 2022 Lyons, Gorman, Larkin, Duncan and Hayes-Lattin. This is an open-access article distributed under the terms of the Creative Commons Attribution License (CC BY). The use, distribution or reproduction in other forums is permitted, provided the original author(s) and the copyright owner(s) are credited and that the original publication in this journal is cited, in accordance with accepted academic practice. No use, distribution or reproduction is permitted which does not comply with these terms. 